\section{GUANAJUATO, "CIUDAD PATRIMONIO DE LA HUMANIDAD". ¿OPORTUNIDAD O DESAFÍO PARA EL TURISMO SOSTENIBLE?}

\author{
María Inés Ortiz Álvarez \\ Universidad Nacional Autónoma de México \\ ORCID iD: http://orcid.org/0000-0003-2045-4168 \\ mioa@unam.mx \\ Luz María Oralia Tamayo Pérez \\ Universidad Nacional Autónoma de México \\ ORCID iD: http://orcid.org/0000-0002-2819-7365 \\ ptamayo@unam.mx \\ Jorge González Sánchez \\ Universidad Nacional Autónoma de México \\ ORCID iD: http://orcid.org/0000-0002-2199-8389 \\ jorgos@unam.mx \\ Alma Villaseñor Franco \\ Universidad Autónoma del Estado de Guerrero, México \\ ORCID iD: http://orcid.org/0000-0001-6748-9662 \\ alvif27@yahoo.com.mx
}

Cómo citar este artículo/Citation: Ortiz Álvarez, M. I., Tamayo Pérez, L. M. O., González Sánchez, J. y Villaseñor Franco, A. (2017). Guanajuato, "Ciudad Patrimonio de la Humanidad». ¿Oportunidad o desafío para el turismo sostenible?. Arbor, 193 (785):a402. doi: http://dx.doi.org/10.3989/arbor.2017.785n3008

Recibido: 30 noviembre 2016. Aceptado: 02 junio 2017.

RESUMEN: La ciudad de Guanajuato fue reconocida en 1988 como Patrimonio de la Humanidad. A partir de este momento el turismo se ha convertido en la actividad que produce mayores recursos económicos para sus habitantes. Debido a las características físicas del lugar, a la estructura de su población y al gran número de visitantes se generan problemas de tránsito, escasez de insumos, aumento de precios y exceso de basura. Para reducir estos inconvenientes, es necesario considerar aspectos relacionados con el turismo sostenible, a fin de estimular el desarrollo local y tomar medidas para salvaguardar el patrimonio de la ciudad evitando su deterioro. En este trabajo se describe el origen de la ciudad y los problemas que afectan a la población local y a la sostenibilidad de su turismo.

PALABRAS CLAVE: Paisaje cultural; carga turística; Guanajuato; México; turismo sostenible; Patrimonio de la Humanidad.

\section{GUANAJUATO, "WORLD HERITAGE CITY». OPPORTUNITY OR CHALLENGE FOR SUSTAINABLE TOURISM?}

Copyright: (C) 2017 CSIC. Este es un artículo de acceso abierto distribuido bajo los términos de la licencia Creative Commons Attribution (CC BY) España 3.0.
ABSTRACT: The city of Guanajuato was recognized in 1988 as a World Heritage Site. Since then, tourism has become the greatest financial resource for the inhabitants. However, the large number of visitors creates traffic problems, rising prices and an increase in the amount of rubbish owing to the physical characteristics of the site and its population structure. To reduce these inconveniences, it is necessary to consider issues related to sustainable tourism. This should stimulate local development, and take action to safeguard the heritage of the city and prevent its decline. This paper describes the origin of the city, and problems affecting the local population and the sustainability of its tourism.

KEYWORDS: Cultural landscape; tourist charge; Guanajuato; Mexico; sustainable tourism; World Heritage. 


\section{INTRODUCCIÓN}

Guanajuato, como muchas de las ciudades patrimoniales de México, tiene una rica herencia cultural en edificaciones, monumentos y costumbres, y las características del relieve montañoso en el que se asienta junto con las adecuaciones que se han adoptado en la misma para favorecer la circulación vehicular y peatonal, le dan un paisaje peculiar y único. La actividad minera desarrollada durante varios siglos en el pasado también le imprimió rasgos propios que evidencian su relevancia de otras épocas. En este trabajo se analizan las características de esta ciudad desde el punto de vista del paisaje cultural y de sus oportunidades para un turismo sostenible.

Con el fin de aprovechar toda esta riqueza patrimonial se realizan eventos que la han convertido en una ciudad de gran prestigio cultural más allá de las fronteras de México. El turismo, tanto nacional como internacional, ha beneficiado a Guanajuato y, si bien esta actividad genera recursos económicos que favorecen la conservación del patrimonio, también provoca una fuerte presión, particularmente sobre los habitantes, quienes tienen sentimientos opuestos respecto al turista; por un lado, saben que deja ganancias en la ciudad que, indirectamente, los favorecen y, por otro lado, ven invadido su espacio común, ya que, siendo una ciudad de menos de cien mil habitantes, el flujo de turistas puede representar un peso excesivo y generar problemas de abastecimiento de alimentos, carencia o contaminación de agua y congestión peatonal, entre otros.

En la actualidad el turista busca algo más que la diversión o el descanso, por lo cual han surgido modalidades como el turismo de aventura, el turismo rural o el turismo cultural, donde el paisaje juega un papel fundamental, ya que enmarca el lugar y es un atractivo adicional. Sin embargo, el turismo también tiene que planificarse, ya que una cantidad inusual de visitantes puede generar problemas a la comunidad local, de ahí la importancia de procurar un equilibrio entre los recursos turísticos que posee el lugar y el desgaste de los mismos, ya que ambos deben ser un complemento.

Con la activación de los principios del desarrollo sostenible se propone el respeto a los valores y principios éticos como: el cuidado de la vida, la integridad, la justicia social y económica, la democracia, la no violencia y la paz, entre otros, los cuales están contenidos en el documento denominado Carta de la Tierra (2006), en el que participaron diversos organismos internacionales encabezados por la Organización de las Naciones Unidas, con el fin de reglamentar la sostenibilidad de los recursos. El desarrollo sostenible supone la elaboración de estrategias para que se utilicen los recursos de manera conveniente, evitando daños al ambiente y el deterioro del patrimonio, para lo cual se señalan a continuación los conceptos teóricos en los que se basa este trabajo:

En primer lugar, la sostenibilidad o sustentabilidad. Este concepto alude al equilibrio entre los recursos y el entorno al que pertenecen; por lo tanto, el objetivo de la sostenibilidad es que las generaciones presentes disfruten del bien común, cuidando que esto no desgaste, prive o comprometa dicho recurso para las generaciones futuras, de manera que su utilización o explotación permita su renovación o cuidado. Lo sostenible tiene que apoyarse en algo, "ser sostenido", es un sistema en desequilibrio que necesita el soporte de un flujo permanente de energía, materia e información. Además, para mantener los niveles requeridos de producción y sostenibilidad, demanda procesos de transformación y artificialización que deberían ser respetuosos con los valores medioambientales. Lo sustentable en cambio, puede sostenerse por sí mismo mediante su propio esfuerzo para equilibrarse, esto se aplica a sistemas específicos de la naturaleza (Mateo Rodríguez, 2012, p. 31).

Otro concepto que hay que considerar es el de paisaje cultural, el cual deriva del paisaje natural y se expresa por los resultados de la actividad humana que lo moldea (Mateo Rodríguez, 2012, pp. 40-42). El turismo sostenible es un potente instrumento que permite garantizar los recursos de los que depende, participando activamente en la estrategia del desarrollo regional (Pérez de las Heras, 2004, pp. 249-252, cita la Carta de Turismo Sostenible); por tanto, en la práctica turística, al proporcionar a los seres humanos los bienes y servicios que requieran, es importante cuidar que estos no vulneren el paisaje natural ni el cultural, además de que dichas actividades deben ser planeadas de manera que proporcionen un recurso económico que permita el mantenimiento y la conservación de los bienes patrimoniales.

Por último, se maneja el concepto de conectividad. "En términos generales, puede entenderse la conectividad como una cualidad que surge y se desarrolla de la existencia de vínculos entre territorios y actividades que se interrelacionan. De esta manera, la representación física del concepto abstracto de conectividad es el de una estructura que está conformada por una red de corredores que sirven para movilizar bienes, servicios, información y personas entre distintos puntos del territorio" (Rozas y Figueroa, 2006). 
Estevan y Sanz (1996) revisan bastante detalladamente la terminología del transporte, y sintetizan una definición de movilidad en distinción a la de accesibilidad, donde la movilidad es un parámetro o variable cuantitativa que mide la cantidad de desplazamientos de las personas o los bienes en un determinado sistema socioeconómico; y la accesibilidad es un parámetro o variable cualitativa que indica la facilidad con que las personas salvan la distancia que los separa de los lugares donde satisfacen sus necesidades o deseos" (Gutiérrez, 2012).

\section{ORIGEN Y DESARROLLO DE LA CIUDAD DE GUANAJUATO}

La ciudad de Guanajuato es una de las ciudades mexicanas que ofrece más importantes atractivos culturales para el turista. La declaración por la Organización de las Naciones Unidas para la Educación, la Ciencia y la Cultura (UNESCO) de esta localidad, en 1988, como Ciudad Patrimonio Mundial es un reconocimiento a los valores que posee, aunque no siempre fue así; por eso el interés de analizar a continuación las características de esta ciudad, las particularidades de su origen y su sostenibilidad en relación con el turismo.

La región en donde se encuentra la ciudad de Guanajuato es montañosa, con declives pronunciados de laderas largas y valles profundos cavados por numerosos escurrimientos provenientes del sector septentrional de la cuenca adyacente a la misma, debido a que el valle longitudinal en el que se encuentra emplazada la ciudad es profundo y su cuenca intermontana tiene dirección perpendicular, simula una barrera orográfica que facilita la concentración del escurrimiento, lo que ha provocado inundaciones y acarreo de escombros cuando se producen lluvias torrenciales.

La ciudad se fundó en 1557 y desarrolló rápidamente, debido al descubrimiento cinco años antes de las ricas vetas minerales que hiciera el capitán español Juan de Jaso, posiblemente cumpliendo órdenes de Hernán Pérez de Bocanegra. Así, el primer juez y superintendente de minas, Perafán de Rivera, la fundó con el nombre de Santa Fe y Real de Minas de Quanaxhuato (Cervantes, 1942). Su nombre, que significa lugar de ranas, fue dado por grupos chichimecas que recorrían la región antes de la llegada de los españoles.

Las ciudades fundadas a causa de afloramientos de depósitos minerales suelen localizarse en zonas montañosas de relieve abrupto, con desniveles y difícil topografía, por lo que sus calles irregulares y angostas les dan aspecto de plato roto. Las minas que fueron la causa de su emplazamiento pronto comenzaron a mostrar la riqueza mineral que poseían; se multiplicaron las excavaciones mineras y aumentó la población, convirtiendo a Guanajuato en una de las principales ciudades de la Nueva España. Al finalizar el siglo XVI había 4.000 habitantes en la localidad. En 1610 ya existían las primeras casas reales -como la finca de Diego Rul, convertida en el Supremo Tribunal de Justicia1-, el convento y la Parroquia de San Diego. Al terminar el siglo XVII Guanajuato tenía 16.000 habitantes; en el siglo XVIII se construyeron los santuarios de Cata y de Guadalupe y se inició la construcción de la Presa de la Olla (Marmolejo, 1973, p. 147). José Antonio de Villaseñor y Sánchez, contador general de Reales Azogues, en su informe al rey (1746-1747) señalaba la importancia de esta ciudad para la Corona Española mediante lo siguiente:

La villa de Santa Fe es la capital de esta jurisdicción... el trato es oro, plata y cobre, que crían los cerros y producen las minas principales... Hállanse en todo el recinto minerales y minas todas de oro y plata... cada una... con su iglesia y su capellán y lo mismo sucede con cuarenta y tres haciendas de beneficio de sacar plata, que están en las cañadas... Compónese lo material de la villa de perfectos edificios y casas, aunque no muy concertadas sus calles por el mal terreno de su fundación; tiene tres conventos de religiosos: el de San Pedro de Alcántara de franciscos ${ }^{2}$ descalzos, el de la Compañía de Jesús y el de la Hospitalidad de Betlemitas... Tiene su iglesia parroquial... en ella se venera una imagen de la Santísima Virgen María Nuestra Señora de Guanajuato, que condujo un devoto caballero a estas regiones desde la ciudad de Granada... El cuerpo político se compone de un alcalde mayor, ... dos alcaldes ordinarios, ... Agrégase al trato de la minería el de las ropas, sedas y mercerías de Castilla, que hay en ochenta tiendas de grueso, y más de cuarenta de géneros de la tierra, sin setenta y tres que hay en los principales reales de minas, de las que se surten operarios y mineros; su vecindario es muy lúcido por lo que respecta a españoles, incluyéndose en el número de más de cinco mil familias las de los mestizos, mulatos y otras (Villaseñor y Sánchez, 1746/2005, pp. 428-430).

En 1793, según el censo de Revillagigedo, Guanajuato contaba ya con 32.098 habitantes y era el principal centro productor de plata de la Nueva España (Humboldt, 1822/2004, p. 38). En 1803, Humboldt cuantificó 41.000 habitantes en la Ciudad de Guanajuato y agregando las minas de sus inmediaciones, la población aumentaba en 29.600 , resultando un total de 70.600 habitantes (Humboldt, 1822/2004, p. 162). 
La cantidad y belleza de las edificaciones que contenía Guanajuato, sus obras de infraestructura, así como la riqueza de sus minas la hicieron blanco y objetivo para ganar la Guerra de Independencia; con la toma de la Alhóndiga de Granaditas y los sucesos inenarrables del 28 de septiembre de 1810 , se produjo el abandono de las minas, la disminución considerable de sus habitantes y, como consecuencia, la ciudad perdió importancia.

\section{ACCESIBILIDAD Y CONECTIVIDAD DE LA CIUDAD DE GUANAJUATO}

Como se mencionó, desde su fundación Guanajuato se comunicaba con pequeños poblados mineros, minas y haciendas de beneficio, las calles del centro histórico son estrechas, pero de tamaño suficiente para permitir el paso de carretas utilizadas para la minería y aprovisionamiento de todo tipo de materiales y productos del campo, su trazado es irregular adaptándose a las formas del relieve.
La ciudad de Guanajuato, al ser la capital del Estado del mismo nombre, tiene un gran dinamismo económico y en toda su aglomeración urbana se realizan movimientos de personas y mercancías de elevada intensidad, lo que contribuye a intensificar los problemas de vialidad del área central. La construcción de numerosos túneles, uno de sus rasgos más peculiares, y la vía de circunvalación de la ciudad no han sido suficientes para mejorar el tránsito, por lo que se presentan puntos conflictivos ocasionando congestionamientos, especialmente en las horas punta, y en las avenidas y calles donde circulan diversas rutas del transporte público, servicio que registra graves deficiencias en tiempos de recorrido y coberturas horarias -sobre todo en la zona sur-, además de saturación de vialidades al interior de la ciudad, ya que por la misma calle pasan, en ocasiones, más de tres rutas (Programa de Gobierno Municipal de Guanajuato 2012-2015).

Figura 1. Mapa de vialidades de la ciudad de Guanajuato, México

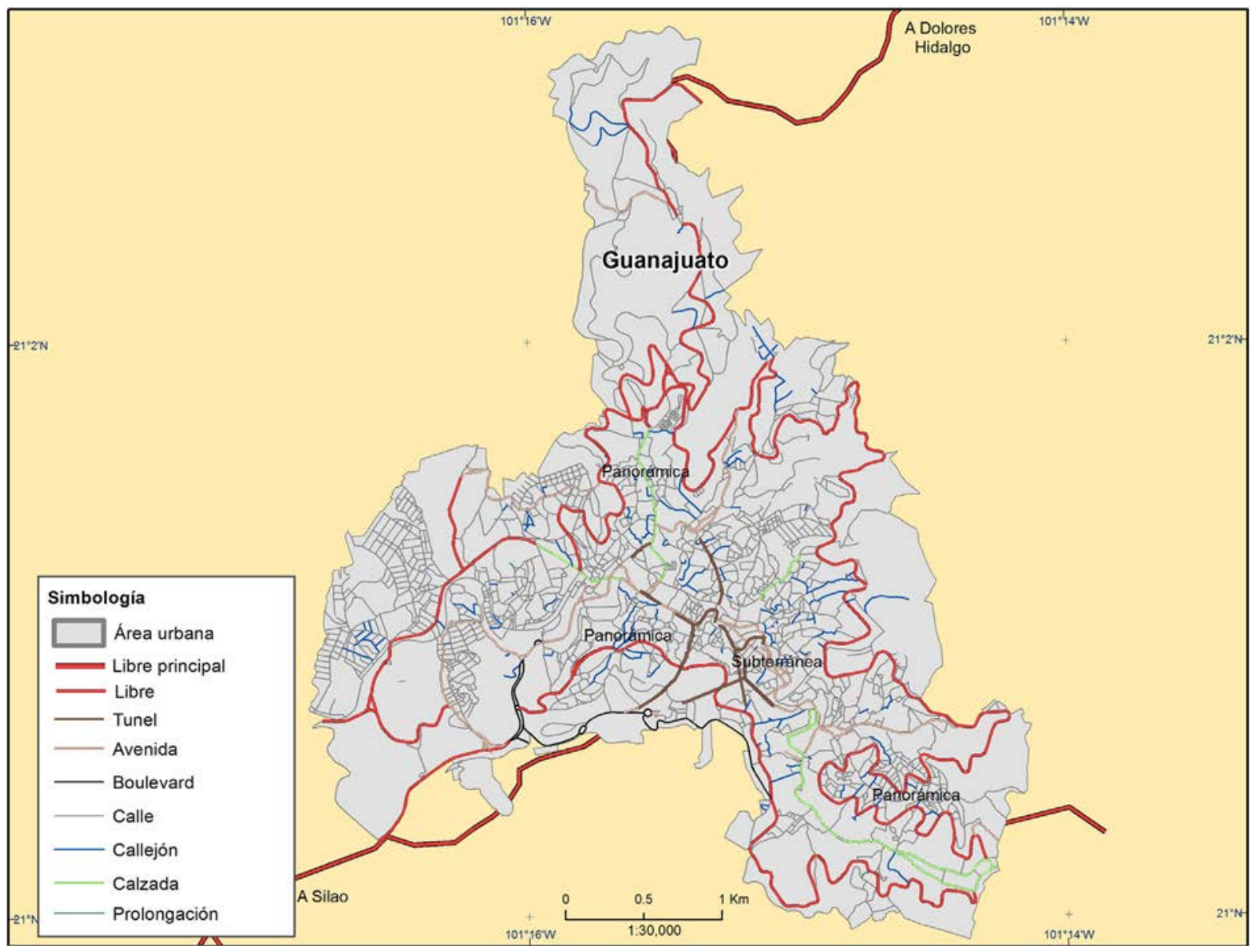

Fuente: Marco Geoestadístico Nacional y Conjunto de Datos Vectoriales de Carreteras y Vialidades Urbanas. 
La topografía del emplazamiento en donde se asienta la ciudad dificulta el acceso y comunicación entre las diferentes zonas; el centro histórico tiene poca capacidad vial por lo que es común que se produzcan embotellamientos de tráfico en las calles y paraderos, por esta razón se estaciona en las calles subterráneas ocasionando mayores problemas a la circulación.

En general el transporte público no es muy usado por los turistas, ya que el centro histórico comúnmente se recorre caminando. No obstante, para el programa Observatorio Turístico, el servicio que prestan los taxistas es bueno (Perfil del Visitante. Guanajuato 2015). Por otra parte, los autobuses actuales se están sustituyendo por camionetas tipo Urban, que son más convenientes, ya que tienen menores dimensiones y contaminan menos, tienen mejor aspecto (son nuevas) y se mueven con mayor facilidad por las calles (figura 1). Un elemento singular de comunicación es el Funicular de Guanajuato, que permite a los turistas transportarse cómodamente desde el centro de la ciudad al monumento en honor al Pípila (héroe local), en el Cerro de San Miguel con un mirador desde el que se puede admirar casi toda la ciudad.

El centro histórico se ve afectado por la cantidad de vehículos particulares y de rutas de transporte que a diario circulan por sus calles, al igual que la imagen urbana por la presencia de automóviles particulares y camiones de grandes dimensiones, a lo que se añade la intensa presencia y movilidad de los turistas. El 56\% de los visitantes a la ciudad de Guanajuato utiliza automóvil propio, el 34\% autobús, el 7\% avión, el 2\% automóvil rentado y el $1 \%$ vehículos de empresas (Perfil del Visitante. Guanajuato 2015).

En la zona sur se presenta una estructura vial incompleta y discontinua, a pesar de tener mejores condiciones topográficas, debido al crecimiento urbano desordenado y a la subdivisión de parcelas que ha ocasionado dicha discontinuidad.

La estructura vial existente se concentra en la zona histórica de la ciudad y la carretera panorámica es la alternativa periférica. La falta de comunicaciones transversales y la traza urbana tendió a reproducir la problemática del centro urbano hacia la autopista Guanajuato-Silao, lo que ha dado lugar a un "cuello de botella", generando una desarticulación entre las áreas del sur-poniente -de reciente desarrollo- y las zonas de la Cañada al norte.

Guanajuato se caracteriza por su actividad turística principalmente de fin de semana; los visitantes pueden llegar tanto en automóvil como por transporte público de pasajeros. Su situación central permite que los turistas provengan de las principales ciudades situadas en un radio menor de 400 kilómetros. Además, durante los diversos eventos que se llevan a cabo en la ciudad a lo largo de todo el año, se emplean autobuses de alquiler procedentes de diversos lugares, con tarifas reducidas hasta de un $50 \%$. En temporada de grandes flujos de visitantes, llegan a la ciudad gran cantidad de autobuses, ocasionando graves problemas de estacionamiento y de todo tipo que generan situaciones de tensión y de descontento por parte de los residentes habituales.

En la última década se ha construido un espacio de aparcamiento para más de 300 automóviles particulares en un intento de resolver uno de los problemas de sustentabilidad del turismo, además se dispone con el mismo objetivo del espacio rehabilitado de la antigua estación del ferrocarril que brinda posibilidades de estacionamiento a los autobuses foráneos (de la Calle y Ruiz, 2014, p. 258), aunque la movilidad y accesibilidad no quedan totalmente resueltas puesto que no se cuenta con un transporte colectivo que acerque a los visitantes desde aquí al centro de la ciudad. Otra de las carencias que resulta prioritario resolver para un desarrollo turístico organizado es la falta de puntos oficiales que proporcionen información a los visitantes y turistas. Ese vacío es cubierto por guías locales que captan así más clientes (Ruiz, 2011), si bien se encuentran con la competencia de personas de escasa formación que integran lo que podríamos dominar sector "informal" del turismo que tiene peso y relevancia económica.

\section{TURISMO Y PATRIMONIO EN LA CIUDAD DE GUANAJUATO}

El actual Programa Estatal de Turismo del Estado de Guanajuato, como programa sectorial, así como la Ley de Turismo para el estado de Guanajuato y sus municipios hacen patente su interés por fortalecer un sector turístico competitivo, sustentable e incluyente, el cual tenga presencia y posicione a la Ciudad de Guanajuato como un destino cultural privilegiado de México, tanto a escala nacional como internacional, teniendo en cuenta sus valores relacionados con su historia, identidad, tradiciones y modernidad.

Una de las principales líneas estratégicas propuestas hace referencia a la sostenibilidad turística, considerando que la importante diversidad de recursos turísticos de la ciudad debe ser aprovechada tanto en el presente como en el futuro, sin perjuicio para la calidad de vida de la población local. Así el objetivo cen- 
tral es consolidar de manera autosostenible la oferta turística y todo el potencial de desarrollo económico que comporta. De forma específica, los objetivos propuestos en el Programa para el Desarrollo Regional Turístico Sustentable (PRODERETUS) plantean: "contribuir al fortalecimiento de las ventajas competitivas de la oferta turística nacional... modernizar la infraestructura y el equipamiento... contribuir en el cuidado y preservación del patrimonio cultural, histórico y natural de los sitios turísticos... fomentar la innovación de productos turísticos, para el desarrollo de una oferta turística complementaria y diversificada".

Así, la ciudad de Guanajuato, situada en el municipio y estado del mismo nombre, puede ser considerada como uno de los sitios de importancia singular por su riqueza patrimonial, la cual adquiere una distinción a través la UNESCO, organismo que determina los sitios que formarán parte del Patrimonio Mundial de la Humanidad, en cuya lista fue incluida la Zona de Monumentos Históricos de Guanajuato y Minas Adyacentes el 9 de diciembre de 1988, atendiendo a los siguientes criterios básicos:

I) Representar una obra de arte del genio creador humano, ya que la Ciudad posee ejemplares del arte de arquitectura barroca donde el estilo churrigueresco es patente.

II) Atestiguar un intercambio de influencias considerable, durante un periodo concreto o en un área cultural o determinada, en los ámbitos de la arquitectura o la tecnología, las artes monumentales, la planificación urbana o la creación de paisajes. Este aspecto dio liderazgo en las diversas poblaciones mineras del centro norte de México desde el siglo XVI hasta el XVIII.

III) Constituir un ejemplo eminentemente representativo de un tipo de construcción o de conjunto arquitectónico o tecnológico, o de paisaje que ilustre uno o varios periodos significativos de la historia humana. Su destacada arquitectura de edificios gubernamentales, haciendas, casas y sitios religiosos emblemáticos del barroco del siglo XVIII muestra en el paisaje los aspectos más relevantes de un próspero desarrollo industrial y económico durante una larga época ligada a la minería como actividad principal, con una perfecta adaptación de la estructura y trama urbanas a la topografía, con el desarrollo de obras hidráulicas e instalaciones inherentes a la explotación minera.

IV) Estar directa o materialmente asociado con acontecimientos o tradiciones vivas, con ideas, creencias $u$ obras artísticas y literarias que tengan un significado universal excepcional. (El Comité consideró que este criterio debería ser utilizado preferiblemente de manera concomitante con otros criterios).

En la ciudad de Guanajuato existe un patrimonio urbano que la revela como Zona de Monumentos Históricos contemplada, de forma legal, por la Ley del patrimonio cultural del estado de Guanajuato. Dicha ley, además de la conservación de los bienes inmuebles históricos, hace referencia a la protección de todo el patrimonio cultural, de acuerdo a criterios de clasificación de interés social y nacional. Las disposiciones establecidas son de orden público y de rango federal, siempre con un fuerte carácter presidencialista, puesto que, según la legislación mexicana de protección del patrimonio, es el presidente de la República el máximo responsable y quien otorga la calificación de bienes protegidos, eso sí, en todo momento con la implicación de los distintos niveles de gobierno.

De todos modos, la preocupación por la conservación del patrimonio monumental y artístico de Guanajuato, con sus consiguientes efectos sobre la actividad turística, es muy anterior a su declaración por la UNESCO como Ciudad Patrimonio de la Humanidad y a la ley de 2006 antes comentada. La Ciudad de Guanajuato ya fue declarada Zona de Monumentos Históricos el 28 de julio de 1982, acogiéndose a lo dispuesto por la Ley Federal sobre Monumentos y Zonas Arqueológicos, Artísticos e Históricos de 1972, reformada en 2015 (Diario Oficial de la Federación, 28 enero 2015), que incluye nuevos valores arquitectónicos populares y artísticos y otros espaciales como plazas, jardines, rinconadas, plazuelas, callejones y, en general, la traza urbana como elemento histórico de valor incalculable (Gálvez González, 1996, pp. 27-29). En este sentido tampoco hay que olvidar los efectos sobre la conservación y protección del patrimonio que ha tenido y tiene la Convención del Patrimonio Mundial Cultural y Natural de la UNESCO en París de 1972 (del 17 al 21 de octubre de ese año).

\subsection{Poblado minero de gran importancia}

Como se mencionó, el desarrollo de la minería propició la fundación de esta ciudad en 1554, perteneció al Distrito Minero de Guanajuato como Real de Minas de Guanajuato y se erigió como alcaldía mayor. Recibió el título de Villa 26 de octubre de 1679 por decreto del virrey Enrique de Rivera; en 1741 por orden del rey Felipe $V$ se le otorgó la categoría de muy noble y leal ciudad de Ciudad de Santa Fe y Real de Mi- 
nas de Guanajuato; en 1786 fue nombrada capital de la Intendencia de Guanajuato y, desde 1824, capital del estado del mismo nombre. Cabe señalar que, en la época juarista, en 1858, fue declarada capital de la República. Como sitio minero de gran relevancia en el centro de México concentró espacios de gran calidad arquitectónica para la administración, uso residencial, centros culturales y religiosos. Su patrimonio históri$\mathrm{co}$, desde el siglo XVI, contiene monumentos civiles, religiosos, gubernamentales y otros de diversa índole, que conforman el paisaje urbano. Es importante destacar que, debido a que la ciudad se desarrolló en la cañada formada por el río Guanajuato, se construyeron numerosos puentes para su comunicación, ya que las avenidas del río afectaban a la ciudad con numerosas inundaciones. Con el fin de remediar esto, se realizaron obras para modificar las corrientes y darle seguridad a la ciudad. Los cambios permitieron que, años más tarde, algunos tramos del cauce se embovedaran dando lugar a túneles que hoy en día constituyen algunas de las calles subterráneas, habilitadas como medios de comunicación y que constituyen uno de los más importantes atractivos turísticos de la localidad (Vázquez González, 2011).

A todo lo anterior, como reclamo para el turismo cultural, se añade el protagonismo que confiere a Guanajuato la celebración de eventos internacionales entre los que destaca sobremanera el Festival Internacional Cervantino, sin lugar a dudas el acontecimiento que más ha contribuido a proyectar la imagen de esta ciudad en el mundo, no solo como capital estatal sino también como ciudad turística de clara vocación cultural, con diversos matices y estilos (figura 2).

Figura 2. Mapa de diversidad monumental y cultural de la Ciudad de Guanajuato

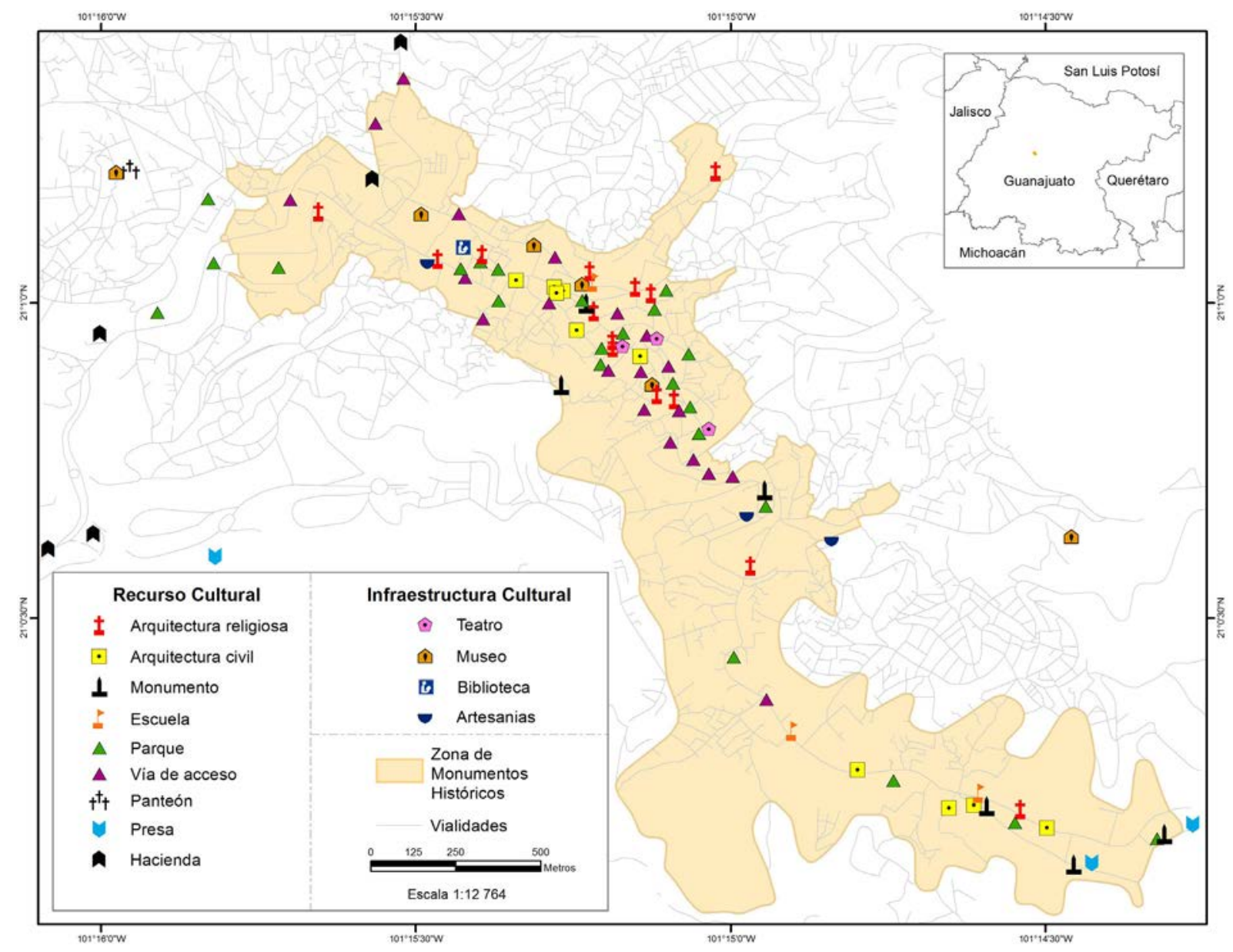

Fuente: Elaborado con base en Vázquez González (2011), Marco Geoestadístico Nacional. 
Actualmente la sobreutilización de la ciudad por actividades múltiples y diferenciadas, pero también y de manera muy intensa por el turismo, provoca fuertes impactos paisajísticos en el interior de la ciudad, no siempre favorables para la preservación de los valores patrimoniales, y sobre todo en la periferia urbana, donde además proliferan los asentamientos formales e informales de carácter residencial como consecuencia del proceso de urbanización del conjunto del país (Garrocho Rangel, 2013). Esta presión en la ocupación del suelo bajo la indetenible urbanización (Gálvez González, 1996, p. 75) amenaza zonas de alto valor medioambiental y paisajístico de un medio natural montañoso que también atrae al turismo. De todos modos, la actividad turística cultural en torno a los principales recursos patrimoniales se desarrolla principalmente en la Zona de Monumentos Históricos, dentro del área de $14.6 \mathrm{~km}$ delimitada perimetralmente por el trazado de la carretera panorámica, que se extiende sobre $1.9 \mathrm{~km}^{2}$, cubriendo aproximadamente 175 manzanas. Es recomendable el establecimiento de itinerarios para visitar esta y hacer recorridos por las vías peatonales y de comunicación que forman un rico entramado, tanto por superficie como de forma subterránea, a fin de ejercer cierto control del daño patrimonial.

El otro gran atractivo turístico está constituido por la zona natural-cultural denominada de Minas Adyacentes, que se extiende fuera del anterior perímetro monumental y corresponde a las explotaciones mineras que han sido durante siglos, desde el XVI, la base de la riqueza de la ciudad y de la calidad artística de sus construcciones, tanto religiosas como civiles. Se trata de unos típicos paisajes de la minería recuperados en muchos casos para la visita turística, algunos tan emblemáticos como el de la mina La Valenciana. Estos lugares muestran no solo los antiguos sitios de exploración, explotación y transformación de los recursos minerales, perfectamente acondicionados para la visita, sino los asentamientos poblacionales a los que dieron origen y que en algunos casos se acompañan de construcciones de excepcional calidad artística como la iglesia de San Cayetano, vinculada a la mina a la que se ha hecho antes mención, La Valenciana. La iglesia, hecha construir entre 1765 y 1788 por Antonio de Obregón y Alcocer, el Conde de Valenciana y propietario original de la mina, es una de las muestras más representativas del barroco mexicano. En esta zona de Minas Adyacentes se ubica también la presa para abastecimiento de agua de la ciudad denominada de la Olla, construida en 1746, y punto central y de justificación de las importantes Fiestas de
San Juan y Presa de la Olla, de 16 a 26 de junio. En su entorno la alta burguesía del Bajío levantó en el siglo XIX espléndidas mansiones de estilo victoriano que hacen de este espacio uno de los más singulares y de más belleza de Guanajuato, permitiendo su calificación como paisaje cultural merecedor de protección especial por sus valores patrimoniales (Zárate Martín y Ortiz Álvarez, 2014). En definitiva, toda la zona de Minas Adyacentes constituye un recurso de enorme potencial de desarrollo turístico a condición de encajarlo en un proyecto de desarrollo integral del turismo de la ciudad, desde luego con criterios de calidad y sostenibilidad y para participar todos los agentes económicos, sociales y políticos del turismo.

\section{EVOLUCIÓN DE LA ACTIVIDAD TURÍSTICA Y PER- CEPCIÓN DE LOS HABITANTES DE GUANAJUATO CON RESPECTO AL TURISMO}

La evolución urbana reciente de la ciudad de Guanajuato muestra ciertas peculiaridades que se deben destacar en cuanto al manejo y protección del patrimonio histórico de la ciudad y a su aprovechamiento turístico, debido a su particular emplazamiento de ladera de montaña. En 1990 alcanzó su máximo desarrollo demográfico, con la ocupación prácticamente completa de todos los espacios habitacionales disponibles, por lo que, a partir de esos años, el crecimiento de la ciudad tuvo que dirigirse hacia el sur, primero a la vecina localidad de Marfil y, posteriormente, a La Yerbabuena, las cuales han absorbido la demanda más reciente de vivienda y de otros usos urbanos. En general, se puede afirmar que esta dinámica urbana ha tenido efectos positivos, facilitando los trabajos de rehabilitación y mantenimiento de la zona patrimonial; sin embargo, cabe recalcar que la mayor parte de la infraestructura y la oferta turística se concentran en el centro histórico de Guanajuato, originando a menudo y sobre todo durante el Festival Cervantino una excesiva carga turística que habría que gestionar conforme a criterios de sostenibilidad, entre otras razones para reducir problemas de alojamiento, de congestión de tráfico, de abastecimiento de agua y de alimentos, que provocan inconvenientes a los vecinos y justifican por su parte actitudes no siempre favorables al turismo, a pesar de coincidir mayoritariamente en la opinión de que constituye una importante fuente de ingresos y de actividad para la ciudad.

En la información censal de 2010 la población de Marfil y La Yerbabuena solo representaron poco más de la tercera parte (34.3\%) de la población total de la ciudad (tabla 1). 
Tabla 1. Población y crecimiento de la ciudad de Guanajuato y áreas urbanas conurbadas, 1990-2015

\begin{tabular}{|c|c|c|c|c|c|c|c|c|c|}
\hline \multirow{2}{*}{ Localidad } & \multicolumn{6}{|c|}{ Población total } & \multicolumn{3}{|c|}{ Crecimiento medio anual (en \%) } \\
\hline & 1990 & 1995 & 2000 & 2005 & 2010 & $2015 *$ & $1990-2000$ & $2000-2010$ & 2010-2015 \\
\hline Guanajuato & 73.108 & 69.970 & 74.874 & 70.798 & 72.237 & 70.954 & 0.2 & -0.4 & -0.36 \\
\hline Marfil & 4.193 & 11.516 & 14.480 & 23.076 & 29.375 & 41.839 & 13.2 & 7.3 & 7.33 \\
\hline Yerbabuena & 1.431 & 2.650 & 4.159 & 7.690 & 8.399 & 11.936 & 11.3 & 7.3 & 7.28 \\
\hline Totales & 78.732 & 84.136 & 93.513 & 101.564 & 110.011 & 124.572 & 1.7 & 1.6 & 1.6 \\
\hline
\end{tabular}

Nota: * Proyección

Fuente: Cálculos propios con base en la información de los censos y los conteos de población del Instituto Nacional de Estadística y Geografía.

La declaración de Guanajuato como Ciudad Patrimonio de la Humanidad supuso un importante revulsivo para el desarrollo turístico de la ciudad. De 323.600 turistas en aquella fecha, 1988, se ascendió a 766.600 en 2015 , más del doble. A lo largo de esos años la tendencia del crecimiento ha sido continua, sobre todo desde 2004, aunque también se han registrado variaciones importantes en algunas ocasiones. Por otra parte, el análisis de los datos oficiales, muestra su consolidación como destino que atrae principalmente a turistas nacionales, los cuales representaron el 98,1\% del total en 2015 y, en valores absolutos, este flujo ha registrado aumentos significativos, mientras que el volumen de turistas extranjeros siempre ha sido minoritario, incluso este segmento de visitantes registra en los años recientes una ligera tendencia a reducir su participación en el total de turistas.
De modo paralelo al crecimiento de la afluencia de turistas, la ciudad de Guanajuato ha incrementado también de manera importante su oferta hotelera. En 1988 contaba con 677.300 habitaciones disponibles y en 2015 llegaron a un cómputo final de 1.083 .3 al año (figura 4). Su aumento ha sido del $58,51 \%$ respecto a la primera fecha considerada, mientras que el de turistas ha sido ligeramente inferior, del $53,61 \%$ en el mismo periodo. Sin embargo, el promedio de cuartos ocupados y el promedio porcentual de ocupación hotelera en general mantienen valores bajos, menores del $45 \%$ con respecto a la oferta total a lo largo del periodo. Esta información evidencia algunas de las debilidades a las que se enfrenta la actividad turística de Guanajuato; en promedio la estancia media de los turistas es baja, inferior a 1.8 noches, a lo que se

Figura 3. Llegada de turistas nacionales y extranjeros a la ciudad de Guanajuato, 1988-2015

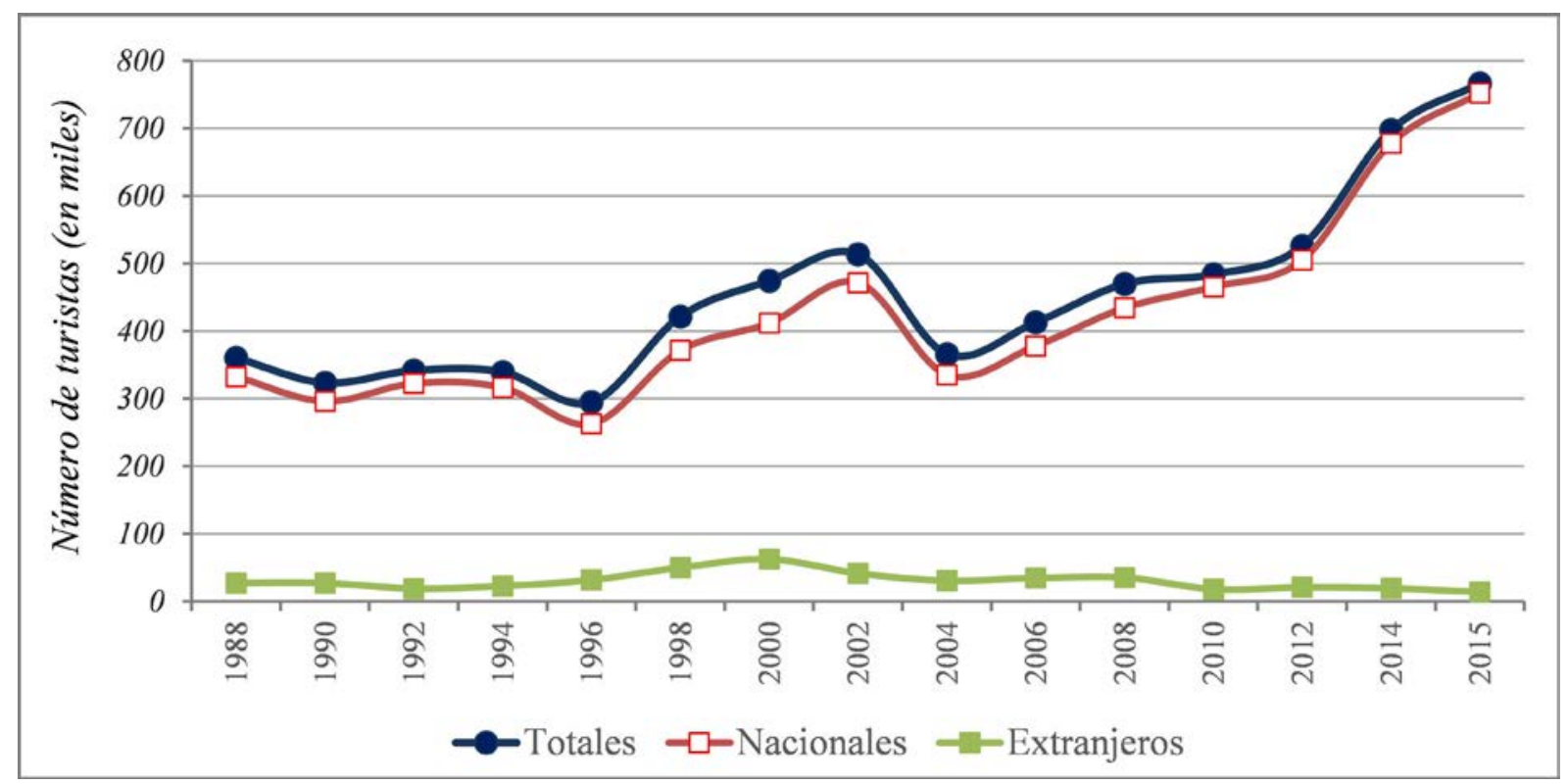

Fuente: Compendio Estadístico del Turismo en México 2016. 
añade que es básicamente un destino turístico de fin de semana, donde el $64.2 \%$ de la afluencia de turistas se concentra entre el viernes y el domingo (Perfil del Visitante. Guanajuato 2015).

A los hechos anteriores se añade la insuficiencia de la oferta hotelera para acoger al elevado número de visitantes que se concentran en determinados periodos del año. Así, la población local refiere que, en temporada de gran demanda hotelera, algunos turistas nacionales, al no alcanzar lugar en algún hotel, duermen en automóviles que se estacionan en las vías subterráneas, lo que provoca malestar y descontento entre los residentes, ya que también esos turistas generan basura, suciedad y malos olores, entre otros inconvenientes.

A lo largo del año, los meses de máxima afluencia de turistas a Guanajuato son durante dos de los periodos tradicionales de vacaciones familiares: el verano y la semana santa, además del mes de octubre, cuando se celebra el Festival Internacional Cervantino. En julio de 2015, Ilegaron 90.400 turistas, en abril 62.900 y en octubre 74.700 , en conjunto en estos tres meses se concentró el $29.7 \%$ del total de turistas que recibió Guanajuato en ese año, y son consecuentemente los meses que registraron los mayores porcentajes de ocupación hotelera (Figura 5). Con estas cifras es posible advertir que, durante los meses de máxima demanda, el número de turistas casi iguala al número de habitantes del área urbana de la ciudad patrimonial de Guanajuato, con lo que se duplica la demanda de insumos y de servicios, entre otros efectos.

También se ha producido desde 1988 hasta la actualidad un incremento del rango social y poder económico de los visitantes a la localidad, por otro lado, nada sorprendente si se tiene en cuenta que el turismo cultural urbano va asociado preferentemente a segmentos de población de mayor capacidad adquisitiva y nivel social. En general se puede afirmar que ha cambiado a través del tiempo el perfil socioeconómico del visitante que llega a la ciudad de Guanajuato; así, de acuerdo con la distribución de los turistas según categoría del hotel en que se alojan, en 2015 más de la mitad (54,1\%) se hospedaron en hoteles de cuatro y cinco estrellas, con unos porcentajes de ocupación cercanos al $50 \%$, y solo el $2,1 \%$ en los de una estrella, que tenían los menores porcentajes de ocupación hotelera. Esta situación contrasta notablemente con la distribución registrada en 1992, cuando en este destino turístico no existían hoteles de cinco estrellas y donde el $21 \%$ de los turistas se alojaban en hoteles de una estrella, que alcanzaban ocupación del 60\% (figura 6).

Figura 4. Cuartos disponibles, ocupados y porcentaje de ocupación en la ciudad de Guanajuato, 1988-2015

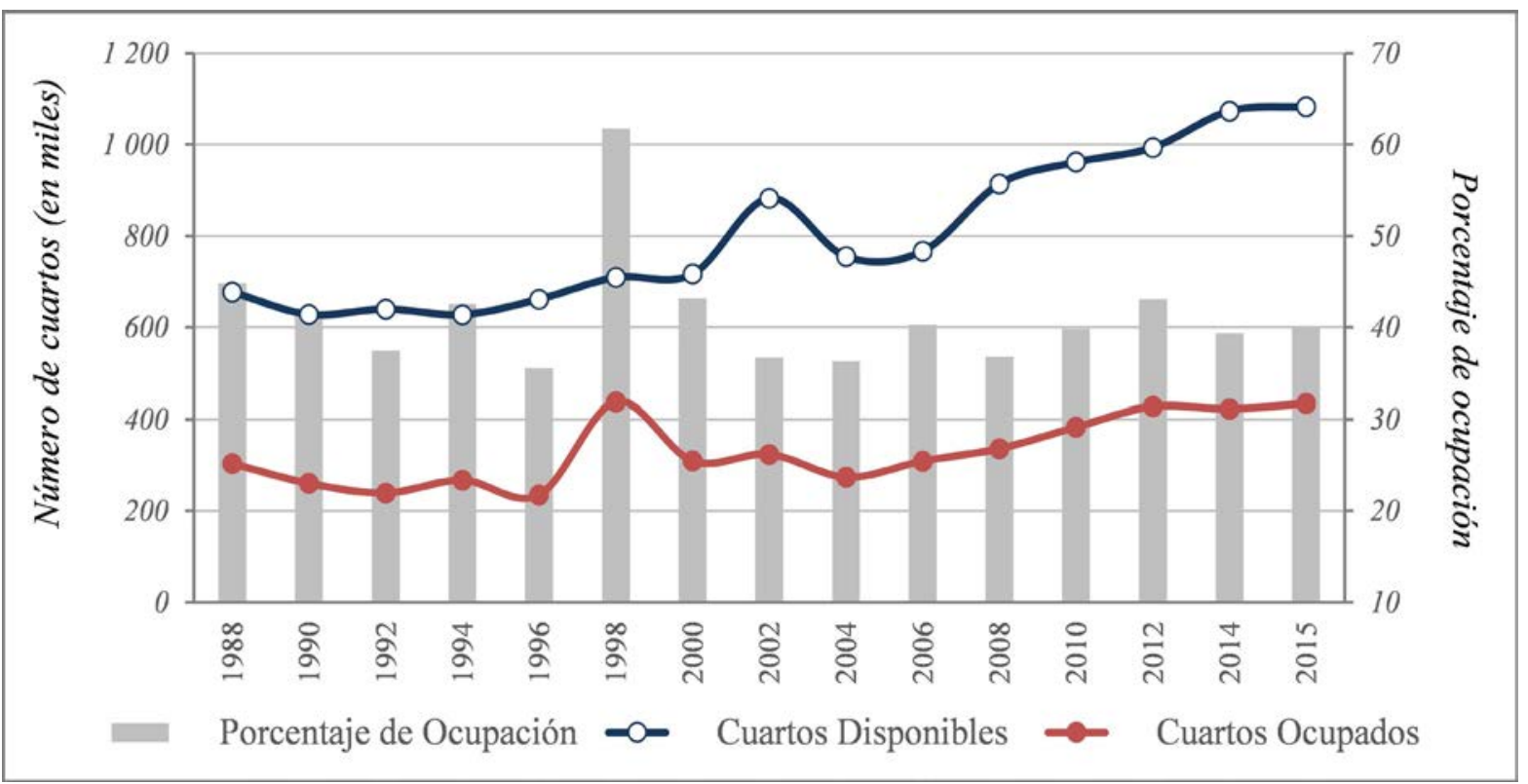

Fuente: Compendio Estadístico del Turismo en México 2016. 
Figura 5. Cuartos disponibles, ocupados y porcentaje de ocupación en la ciudad de Guanajuato en 2015

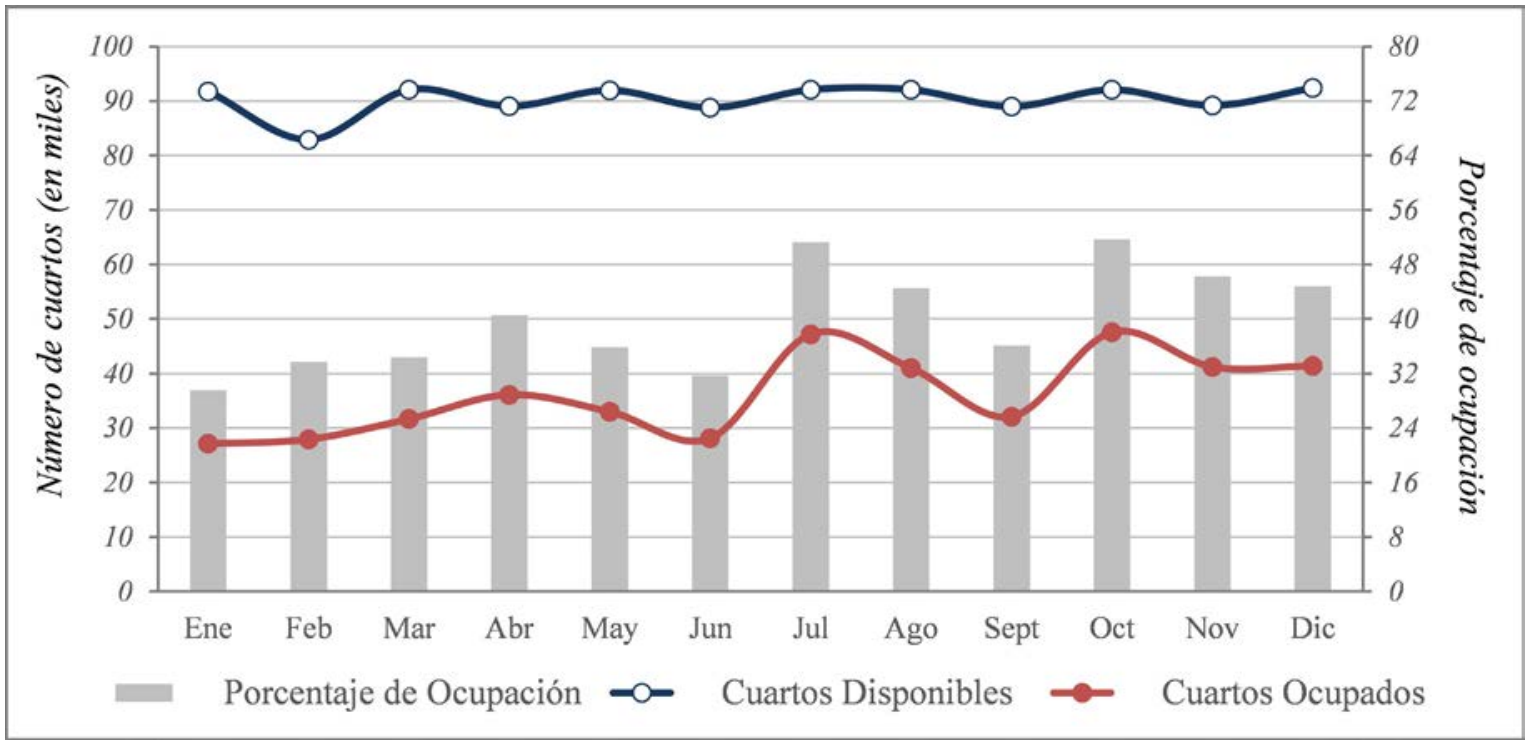

Fuente: Compendio Estadístico del Turismo en México 2016.

Figura 6. Porcentaje de ocupación, según categoría del hotel, en la ciudad de Guanajuato, 1992-2015

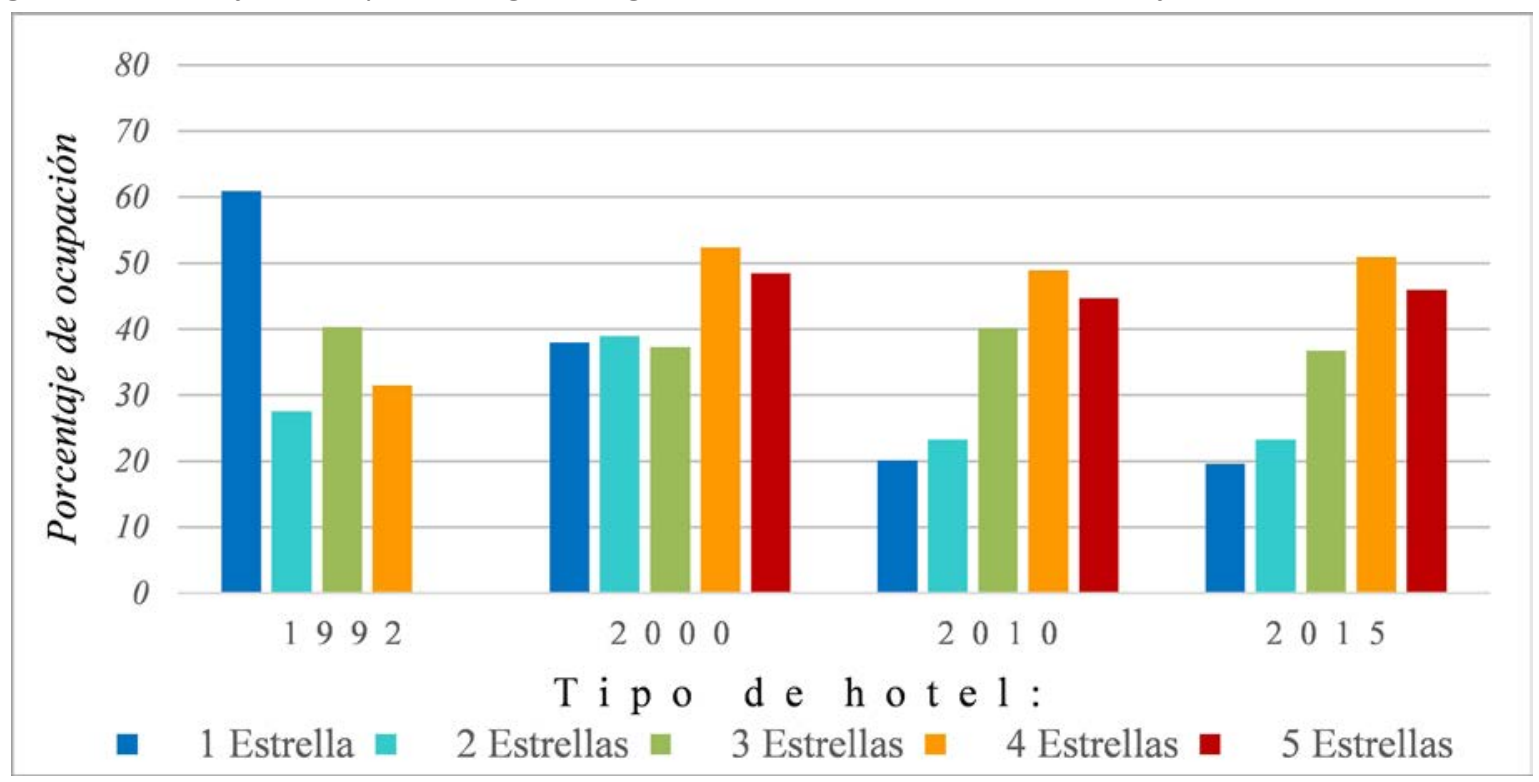

Fuente: Compendio Estadístico del Turismo en México 2016.

Una manera de evaluar el impacto que genera la llegada de visitantes a esta Ciudad Patrimonio es a través del indicador de capacidad de carga de turistas, que relaciona el número de turistas que recibe una localidad con el número de habitantes de ese lugar. Teniendo en cuenta la singularidad de la estructura urbana de Guanajuato ya expresada anteriormente, este indicador se ha calculado en dos versiones, la primera involucra solo el área urbana de Guanajuato, donde se localiza la mayor parte de la infraestructura y de los atractivos de la zona, y la otra considera la aglomeración urbana, que incluye las áreas urbanas de Guanajuato, Marfil y La Yerbabuena. En los dos espacios el indicador de carga turística muestra una tendencia a aumentar; en el área urbana de Guanajuato, se ha pasado de 4,4 turistas por habitante en 1990 a 10,8 en 2015 , y en la segunda versión de este indicador, en el área urbana integrada, de 4,1 en 1990 a 6,1 en 2015 . Son valores inferiores a los anteriores, pero también significativos (figura 7 y tabla 2). 
Tabla 2. Indicadores de actividad turística de la ciudad de Guanajuato, 1990-2015

\begin{tabular}{|c|c|c|c|c|c|c|c|c|c|}
\hline \multirow{2}{*}{ Tipo de actividad } & \multicolumn{6}{|c|}{ Actividad turística } & \multicolumn{3}{|c|}{ Crecimiento medio anual (en\%) } \\
\hline & 1990 & 1995 & 2000 & 2005 & 2010 & 2015 & $1990-2000$ & $2000-2010$ & 2010-2015 \\
\hline Llegada de Turistas & 323596 & 292829 & 474397 & 425471 & 484096 & 766572 & 3.9 & 0.2 & 9.6 \\
\hline Cuartos disponibles & 628481 & 647179 & 716768 & 763585 & 961811 & 1083366 & 1.3 & 3.0 & 2.4 \\
\hline Cuartos ocupados & 260468 & 231963 & 309488 & 297742 & 383253 & 434505 & 1.7 & 2.2 & 2.5 \\
\hline \% de ocupación & 41.44 & 35.84 & 43.18 & 38.99 & 39.85 & 40.11 & & & \\
\hline $\begin{array}{l}\text { Estadía promedio } \\
\text { por noche }\end{array}$ & 1.68 & 1.64 & 1.41 & 1.61 & 1.76 & 1.26 & & & \\
\hline $\begin{array}{l}\text { Capacidad de carga } \\
\text { de turistas (Gto.) }\end{array}$ & 4.4 & 4.2 & 6.3 & 6.0 & 6.7 & 10.8 & & & \\
\hline $\begin{array}{l}\text { Capacidad de carga } \\
\text { de turistas }\left(2^{\mathrm{a}}\right)\end{array}$ & 4.1 & 3.5 & 5.1 & 4.2 & 4.4 & 6.1 & & & \\
\hline
\end{tabular}

Fuente: Cálculos propios con base en la información de Compendio Estadístico del Turismo en México 2016.

Figura 7. Capacidad de carga de turistas de la ciudad de Guanajuato, 1990-2015

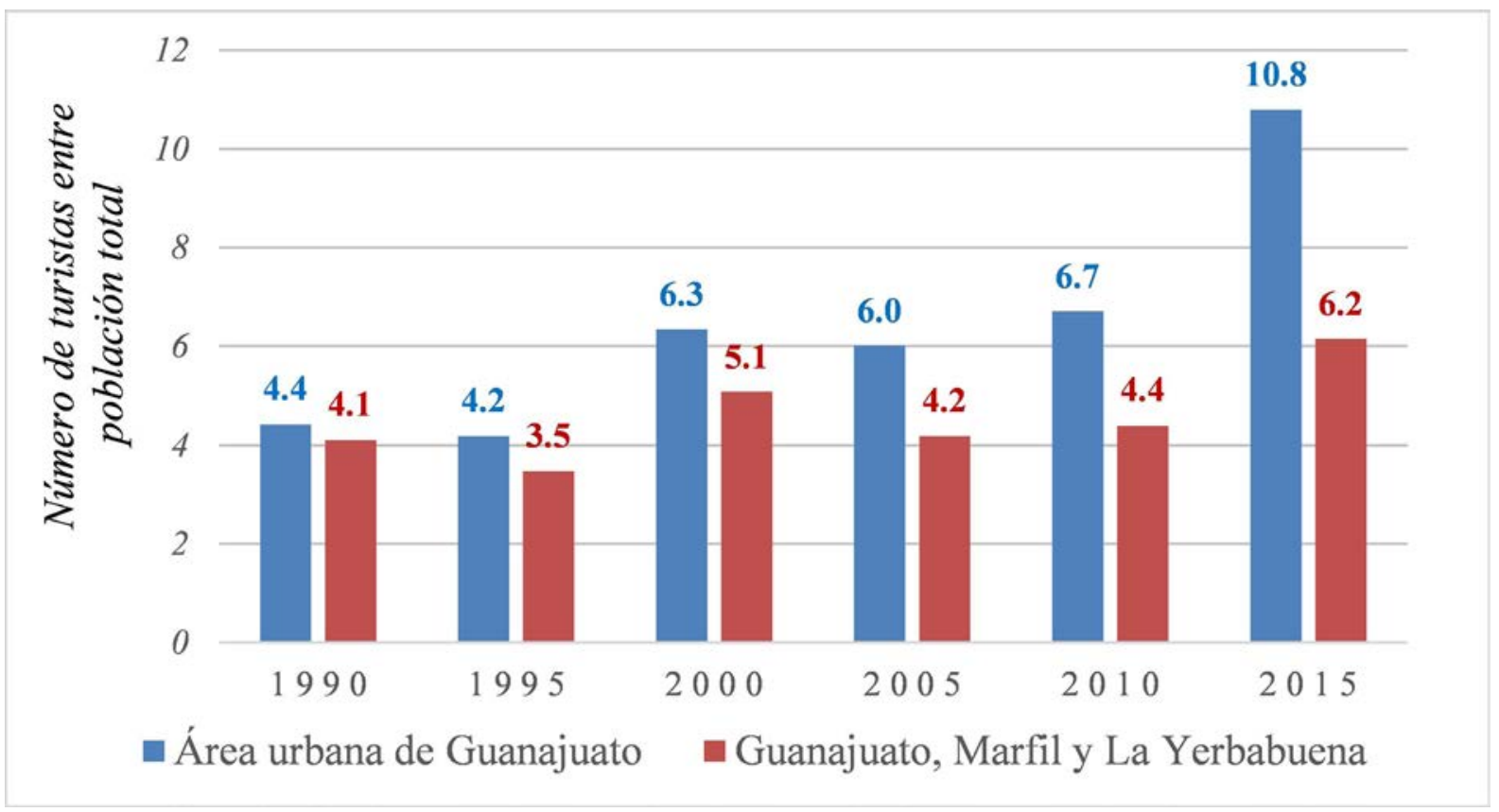

Fuente: Cálculos propios con base en la información del Instituto Nacional de Estadística y Geografía y de la Secretaría de Turismo.

Para conocer la opinión de los habitantes de Guanajuato sobre la actividad turística que se desarrolla en su localidad, se realizó una pequeña encuesta dirigida a la población local; en total se llevaron a la práctica 40 , pero sólo se han tenido en cuenta 37 , debido a que tres encuestados llevaban menos de un año como residentes en Guanajuato, por lo que no se consideró conveniente incluirlos. Otros aspectos que se tuvieron en cuenta fue que se entrevistó a igual número de hombres que de mujeres y se intentó que fueran similares las proporciones por grupos de edad, considerando jóvenes (menores de 30 años), adultos (de 30 a 50 años) y población mayor (más de 50 años de edad), con el fin de que esto no fuera un factor determinante, aunque al analizar los resultados, se pudo comprobar que no hay grandes diferencias en las respuestas por grupos de edad.

En primer lugar, destaca que la mayor parte de los habitantes de Guanajuato son conscientes de residir en una Ciudad Patrimonio de la Humanidad (el 92\%) 
y se sienten orgullos de ello en igual porcentaje, pero la proporción es menor cuando se considera que esta categoría atrae gran cantidad de turistas, al $84 \%$ le complace, pero al $16 \%$ no le agrada que lleguen tantos visitantes; sin embargo, la inmensa mayoría, el $92 \%$, valoran positivamente el aporte que hace el turismo a la economía y a la generación de empleos en la ciudad, la frase más utilizada es "en Guanajuato se vive del turismo".

No obstante, la población local reconoce que existe una serie de problemas generados por la gran cantidad de personas que reciben. Destaca en primer lugar lo referente a la movilidad vehicular dentro de la ciudad, la falta de estacionamientos, junto con problemas de basura y suciedad, como los aspectos más repetidos. Le sigue en importancia el mal comportamiento de los turistas jóvenes, que la población local asocia directamente con el excesivo consumo de alcohol, principalmente durante la celebración del Festival Internacional Cervantino (figura 8). De igual manera, destaca que el $8.9 \%$ de la población encuestada mencionó que la afluencia de turistas no genera ningún problema.

Finalmente, las respuestas de los encuestados ponen de manifiesto que parte de las dificultades a las que se enfrenta la Ciudad Patrimonio de Guanajuato ante la creciente actividad turística tienen que ver con la calidad de los servicios básicos que se brindan a sus habitantes. Por una parte, se señala la existencia de un desabastecimiento de agua en los meses de mayor afluencia turística que no afecta por igual a toda la ciudad, sino a las zonas altas, las más alejadas de los lugares turísticos, y eso se debe a que se atiende preferentemente a la zona hotelera. También se denuncia que durante los periodos de mayor afluencia de turistas el transporte interno se complica por el exceso de tránsito y el cierre de calles, y que, en general, bajo esas circunstancias como se comentó durante la realización de la encuesta, "se tarda más en recibir algún servicio". Por otra parte, también se critica que las tareas de mantenimiento se concentran solo en el área patrimonial, mientras que el resto de la ciudad se deja descuidada. Quizá la frase que resume esta sensación general de la población residente de Guanajuato, es que "todos deberían beneficiarse del turismo".

\section{CONCLUSIONES}

La ciudad de Guanajuato contiene un valioso patrimonio cultural producto de su trayectoria histórica y de paisajes urbanos resultado de aprovechamientos del medio natural por el hombre basados durante siglos fundamentalmente en la minería de la plata. Su declaración como Ciudad Patrimonio de la Humanidad, otorgada por la UNESCO en 1988, contribuyó decisivamente a difundir sus imágenes en el mundo y a aumentar su atracción como destino de interés tu-

Figura 8. Principales problemas que generan los turistas a los residentes de la ciudad de Guanajuato

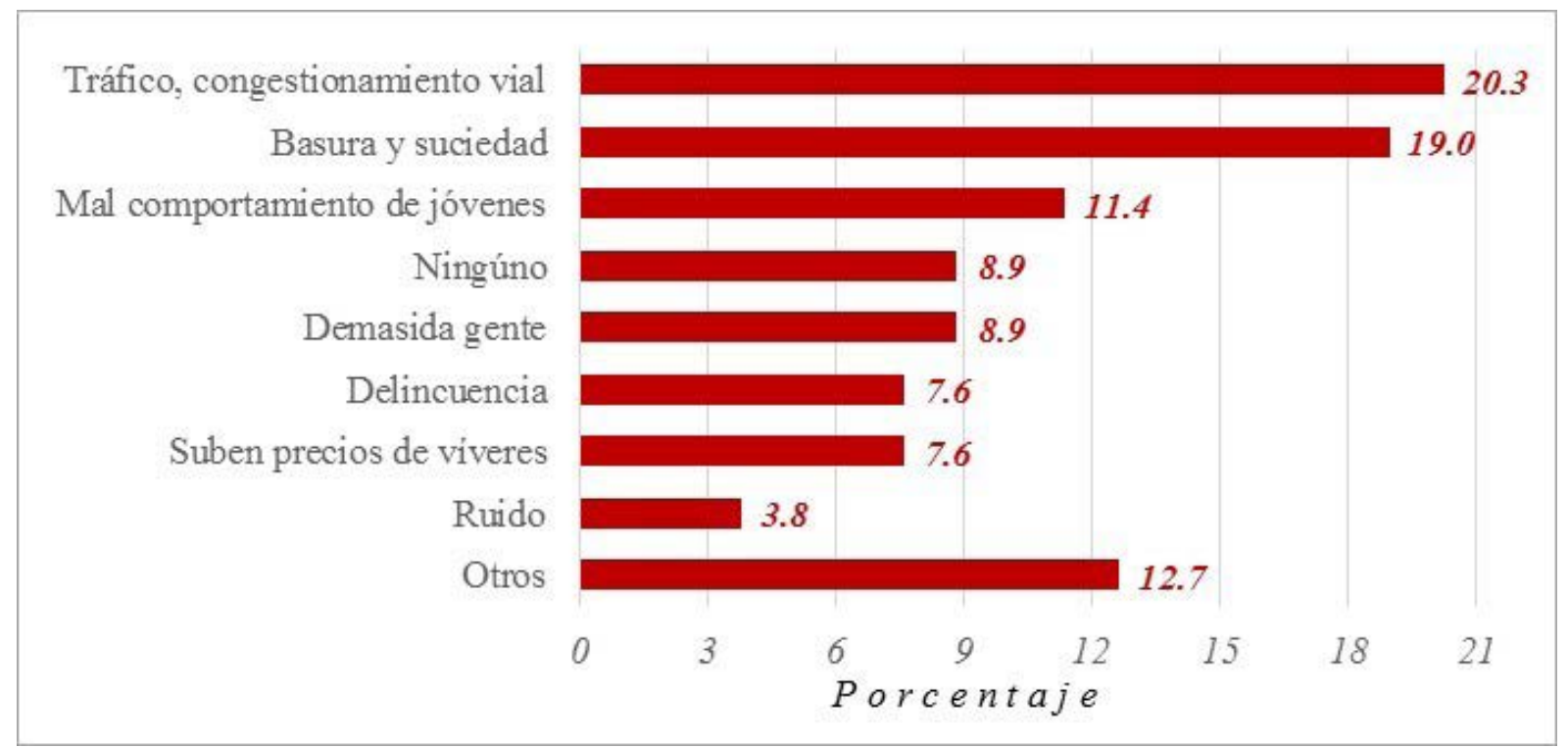

Fuente: Cálculos propios con base en la encuesta e investigación de campo, 2016. 
rístico cultural, como sucede con todas las ciudades del planeta que reciben esta calificación y que les sirve de "marca" de calidad. En la actualidad, el turismo es una de las principales fuentes de ingresos para los habitantes de Guanajuato y de actividad económica para la entidad; por lo tanto, el turismo actúa como oportunidad para su desarrollo local, pero al mismo tiempo constituye un desafío para su futuro por los efectos que provoca en el funcionamiento general de la ciudad y por los problemas que genera para la conservación del patrimonio.

El potencial turístico que ofrece la ciudad al visitante, además de su paisaje y agradable clima, comprende muchos aspectos, principalmente de carácter cultural: museos, teatros, festivales, visitas a sus callejones y sitios típicos. Asimismo, Guanajuato cuenta hoy con hoteles y restaurantes de diversas categorías para todos los presupuestos y actividades culturales distribuidas a lo largo del año que podrían contribuir a reducir la excesiva concentración del turismo en unos meses y días de la semana, así como a aumentar el reducido número de días de estancia, otro de los problemas para una gestión eficaz del turismo. La puesta en valor de todos sus recursos y la creación de la infraestructura de acogida y de restauración a las que se hace referencia han sido posibles gracias a la acción combinada de los diferentes actores sociales de la ciudad y de los responsables públicos y privados del turismo, entre ellos las instancias oficiales del gobierno federal, estatal y municipal, la iniciativa privada y algunas asociaciones civiles.

El esfuerzo de todos los actores públicos y privados de la ciudad ha permitido gestionar recursos económicos, sociales y de planeación que se han invertido para el rescate, rehabilitación y mantenimiento de la riqueza patrimonial, cada vez atendiendo más a criterios de responsabilidad en la protección, conservación, interpretación y presentación de la diversidad cultural y del patrimonio cultural, según se contempla en la Carta Internacional sobre Turismo Cultural para La Gestión del Turismo en los Sitios con Patrimonio Significativo, adoptada por el International Council on Monuments and Sites (ICOMOS) en su 12. - Asamblea General que tuvo lugar en México en octubre de 1999. De ese modo, se ha logrado desarrollar y consolidar una importante y variada oferta de servicios y recursos turísticos que posicionan a Guanajuato como uno de los principales destinos del turismo nacional de México y le abren la posibilidad de convertirse también en un destino turístico internacional privilegiado.
Sin embargo, las acciones emprendidas hasta el momento no están exentas de dificultades, generadas sobre todo por la excesiva concentración de los flujos de visitantes en unos pocos meses por las razones ya señaladas. Como se ha expuesto, se detectan algunos problemas en cuanto a la sostenibilidad de este destino que, de no atenderse, podrían derivar en auténticos obstáculos para la consolidación y desarrollo del turismo pero también para la sostenibilidad del conjunto de la ciudad, entre ellos sobresalen las complicaciones ocasionadas por el exceso de tránsito en periodos del año muy concretos, la escasez de estacionamientos, el incremento en la generación de basura, el aumento de suciedad en los espacios públicos, el ruido y la contaminación del aire, la insuficiencia de insumos y de servicios básicos para atender a las crecientes demandas de la población local y de los visitantes, y principalmente las dificultades para el abastecimiento de agua y el manejo de los residuos. Estos inconvenientes podrían mitigarse mediante una efectiva planeación del turismo que ha de tener en cuenta los criterios de sostenibilidad que parten del Informe Brundtland, del 4 de agosto de 1987, de la Comisión de la ONU sobre el medio Ambiente y el Desarrollo y de la Conferencia de Río sobre la Tierra de 1992 y de manera también muy específica, por tratarse de un destino urbano, de la Nueva Agenda Urbana salida de la Tercera Conferencia de las Naciones Unidas sobre Vivienda y Desarrollo Urbano Sostenible (Hábitat III) celebrada en Quito en octubre 2016. La Nueva Agenda Urbana es un documento orientado a establecer estándares mundiales de logros en el desarrollo urbano sostenible de acuerdo con los valores y principios definidos en la Carta de la Tierra. En ella se establecen pautas que, aplicadas a Guanajuato, podrían contribuir eficazmente a resolver algunos de los problemas ya comentados. De ese modo, el desarrollo turístico de la ciudad quedaría asegurado, así como se garantizarían sus efectos positivos para la conservación y puesta en valor de su rico patrimonio cultural y paisajístico y para la generación de empleo y mejora de la calidad de vida de sus habitantes, aprovechando las oportunidades que generó su declaración como Ciudad Patrimonio de la Humanidad.

La implementación de medidas concretas asociadas a los planteamientos anteriores y comprometidas con el turismo sostenible, como un adecuado plan de manejo y reciclamiento de basura, campañas de concienciación sobre la urgente necesidad de ahorrar el agua y de reducir los niveles de contaminación y de gasto de energía, así como rehabilitar los inmuebles catalogados por el Instituto Nacional de Antropología e Historia (INAH), resolverían los conflictos detecta- 
dos y que en gran parte se pueden interpretar como signos de saturación por la cada vez mayor afluencia de turistas. Dentro de este conjunto de medidas que convendría que formaran parte de un programa estratégico de gestión del turismo de la ciudad, habría que prestar también atención especial a obras de ingeniería que dan singularidad a la ciudad y que han favorecido la conservación de su patrimonio histórico cultural, como son los túneles construidos originalmente para el drenaje de la ciudad en tiempos de la colonia y que actualmente se utilizan para la circulación vehicular. En ese contexto y a pesar de avances realizados recientemente, habría que revisar las emisiones de gases de los motores que pueden dañar las paredes de los túneles y la salud de los habitantes.

Respecto a la sostenibilidad del paisaje urbano, natural y cultural, que rodea a la zona patrimonial sería conveniente implementar acciones que permitan en lo posible contener la invasión de construcciones informales en los cerros que circundan a la ciudad $y$, dado que los residentes son conscientes de que su bienestar e ingresos dependen del turismo, como se ha demostrado en nuestro estudio, convendría involucrarlos en las tareas de mantenimiento y rehabilitación de los distintos espacios, no solo del área patrimonial, sino del área urbana de Guanajuato en su conjunto, de nuevo siguiendo recomendaciones contempladas en la Nueva Agenda Urbana emanada de la Conferencia de las Naciones Unidas sobre Vivienda y Desarrollo Urbano Sostenible (Hábitat III).

Finalmente, habría que tener en consideración todo lo legislado por los distintos niveles de gobierno de México con el fin disponer de programas para el desarrollo del turismo sostenible, en ellos se identifican objetivos, metas, estrategias y políticas acordes con las necesidades de la ciudad, de los turistas y los residentes; sin embargo, en este destino patrimonial todavía no se han logrado implantar integralmente estos programas, lo que constituye una tarea pendiente para impulsar un desarrollo turístico sostenible, aprovechando las oportunidades generadas por la calificación de Guanajuato como Ciudad Patrimonio de la Humanidad y como sucede en todas las ciudades merecedoras de esta calificación.

\section{AGRADECIMIENTOS}

Se hace constar el agradecimiento a Selene Eridani Zaragoza Álvarez, becaria del Instituto de Geografía de la Universidad Nacional Autónoma de México (UNAM) por la elaboración de la cartografía sobre la diversidad monumental y cultural de la Ciudad de Guanajuato, su apoyo en el desarrollo del trabajo y la investigación en campo; a Iván Molina Gardida, por la elaboración de la cartografía de vialidades y a María Elena Cea Herrera por la revisión de estilo.

\section{NOTAS}

1. En la actualidad es el Palacio de Gobierno de la Presidencia Municipal de Guanajuato.

\section{BIBLIOGRAFÍA}

Calle, V. M. de la y Ruiz, L. (2014). Desarrollo e incidencias de las políticas públicas en Guanajuato como destino turístico patrimonial. En: Monterrubio C. J. C. y López L. A. (coords.). De la dimensión teórica al abordaje empírico del turismo en México. Perspectivas multidisciplinarias. México: Universidad Nacional Autónoma de México, pp. 251-264.

Cervantes, E. A. (1942). Bosquejo del desarrollo de la ciudad de Guanajuato. México: s.n.

Estevan, A. y Sanz, A. (1996). Hacia la reconversión ecológica del transporte en España. Madrid: Los libros de la Catarata / Bekaez.
2. También denominados franciscanos descalzos. 
Ruiz, A. (2011). Guanajuato (México): dinámica y estructura de un destino turístico Patrimonio de la Humanidad. [Tesis doctoral inédita]. Universidad Complutense de Madrid: Madrid.

Vázquez González, M. (coord.) (2011). Guía de Rutas Culturales en Guanajuato: Patrimonio Cultural de la Humanidad. México: Universidad de Guanajuato / Guanajuato Patrimonio de la Humanidad.

Villaseñor y Sánchez, J. A. (1746/2005). Theatro americano. Descripción general de los reynos y provincias de la Nueva España y sus jurisdicciones. México: Universidad Nacional Autónoma de México.

Zárate Martín, M. A. y Ortiz Álvarez, M. I. (2014). Estrategias para la conservación y gestión sostenible de los paisajes culturales urbanos en México y España. Espacio, Tiempo y Forma. Serie VI. Geografía, 6-7, pp. 257-280.

\section{Otros recursos}

Carta de la Tierra. Disponible en: http:// cartadelatierra.org/

Carta del Turismo Sostenible. Conferencia Mundial de Turismo Sostenible. Lanzarote, Islas Canarias, España, 27 y 28 de abril de 1995. Disponible en: http:// www.e-unwto.org/doi/abs/10.18111/ unwtodeclarations.1995.21.15.1

Compendio Estadístico del Turismo en México 2016. [En línea]. [Fecha de consul- ta: 20 de agosto de 2016]. Disponible en: http://www.datatur.sectur.gob.mx/ SitePages/CompendioEstadistico.aspx

Conjunto de Datos Vectoriales de Carreteras y Vialidades Urbanas (Edición 1.0). [En línea]. [Fecha de consulta: 20 de septiembre de 2016]. Disponible en: http:// www.inegi.org.mx/geo/contenidos/topografia/vectoriales_carreteras.aspx

Ley del patrimonio cultural del estado de Guanajuato. [En línea]. [Fecha de consulta: 20 de agosto de 2016]. Disponible en: http://docs.mexico.justia.com. s3.amazonaws.com/estatales/guanajuato/ley-del-patrimonio-cultural-delestado-de-guanajuato.pdf

Ley Federal sobre Monumentos y Zonas Arqueológicos, Artísticos e Históricos. [En línea]. Disponible en http:// www.diputados.gob.mx/LeyesBiblio/ pdf/131_280115.pdf

Marco Geoestadístico Nacional. [En línea]. [Fecha de consulta: 20 de septiembre de 2016]. Disponible en: http:// www.inegi.org.mx/geo/contenidos/ geoestadistica/M_Geoestadistico.aspx

Marco Geoestadístico Nacional. Marco Geoestadístico 2014, versión 6.2. [En línea]. [Fecha de consulta: 20 de septiembre de 2016]. Disponible en: http://www.inegi.org.mx/geo/contenidos/geoestadistica/m_g_0.aspx
Perfil del Visitante. Guanajuato 2015. [En línea]. [Fecha de consulta: 20 de septiembre de 2016]. Disponible en: http:// www.observatorioturistico.org/cenDoc/ b0c8b-Perfil-Guanajuato-2015_OT.pdf

Programa de Gobierno Municipal 20122015. Periódico Oficial del Gobierno del Estado de Guanajuato, año C, Tomo CLI, Guanajuato, Gto., 07 de junio de 2013, Número 91, [En línea]. [Fecha de consulta: 18 de septiembre 2017]. Disponible en: https://portalsocial.guanajuato. gob. $\mathrm{mx} /$ sites/default/files/documentos/2013_GUANAJUATO_Programa_ de_gobierno_2012-2015.pdf

Programa Estatal de Turismo. Guanajuato 2013-2018. [En línea]. [Fecha de consulta: 20 de agosto de 2016]. Disponible en: https://portalsocial.guanajuato.gob.mx/ sites/default/files/documentos/2013 SEDETUR_Programa_estatal_de_turismo_guanajuato_2013-2018.pdf

Programa para el Desarrollo Regional Turístico Sustentable (PRODERETUS). [En línea]. [Fecha de consulta: 18 de septiembre de 2017]. Disponible en: https://portalsocial.guanajuato.gob.mx/ sites/default/files/programas_sociales/ reglas_operacion/2014_SECTUR_Reglas\%20de\%200peracion\%20del\%20 Programa\%20para\%20el\%20DesarroIlo\%20Regional\%20Turistico\%20Sustentable\%20\%28PRODERETUS\%29.pdf 